\title{
Research Paper: The Effectiveness of Compassion- focused Therapy for Improving Emotional Control and Reducing the Severity of Pain in Migraine Patients
}

\author{
Zahra Barchakh $^{1}$ (D), Zahra Mardani Valandani ${ }^{*}$ (D), Fariborz Khorvash ${ }^{2}$ (D) \\ 1. Department of Psychology, Payame Noor University, Tehran, Iran \\ 2. Department of Neurology, Neuroscience Research Center, School of Medicine, Isfahan University of Medical Sciences, Isfahan, Iran
}

\begin{tabular}{|c|c|}
\hline $\begin{array}{l}\text { Use your device to scan } \\
\text { and read the article online }\end{array}$ & \\
\hline 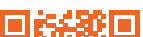 & Chation: Barchakh, Z., Mardani Valandani, Z., \& Khorvash, F. (2021). The Effectiveness of Compassion-focused Therapy for \\
\hline 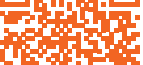 & $\begin{array}{l}\text { Improving Emotional Control and Reducing the Severity of Pain in Migraine Patients. Journal of Practice in Clinical Psychology, } \\
\text { 9(1), 51-60. https://doi.org/10.32598/jpcp.9.1.740.1 }\end{array}$ \\
\hline 口tristis & doi'https://doi.org/10.32598/jpcp.9.1.740.1 \\
\hline
\end{tabular}

(c) (1) (3)

Article info:

Received: 24 Sep 2020

Accepted: 15 Nov 2020

Available Online: 01 Jan 2021

Keywords:

Compassion-Focused Therapy (CFT), Emotional control, Migraine, Pain severity

\section{ABSTRACT}

Objective: Because of the unwanted effects of the patient's migraine headaches and the role of excitement and stress in the development and exacerbation of headaches, migraine headaches are psychosomatic disorders that affect the patients' psychological lives. The present study aimed to investigate the effectiveness of Compassion-Focused Therapy (CFT) for improving emotional control and reducing the severity of pain in patients with migraines.

Methods: A total of 30 patients with migraines referred to Isfahan Al-Zahra Hospital, Isfahan City, Iran, were selected and randomly divided into experimental and control groups. The research instruments included the Emotion Control Questionnaire (ECQ), von Korff's questionnaire for grading the severity of chronic pain, and the Migraine Disability Assessment (MIDAS) questionnaire. The experimental group received eight 90-min sessions of CFT, and both groups took the post-test after finishing the training sessions. Analysis of the data involved both descriptive and inferential statistics, including mean, standard deviation, Multivariate Analysis of Covariance (MANCOVA), and Analysis of Covariance (ANCOVA).

Results: The results showed that the training based on CFT had a significant effect on improving emotional control and its subscales $(\mathrm{F}=21.81 ; \mathrm{P}<0.01)$, as well as reducing pain severity in the patients $(\mathrm{F}=17.21 ; \mathrm{P}<0.01)$.

Conclusion: Therefore, in treating migraine patients, CFT can be a useful supplementary approach along with medications. 


\section{Highlights}

- CFT (Compassion-Focused Therapy) improves emotional control.

- CFT reduces the severity of the pain.

- CFT improves migraine.

\section{Plain Language Summary}

Due to the unwanted effects of the migraine headaches of the patient and the role played by excitement and stress in the development and exacerbation of such headaches, migraine headaches are considered among psychosomatic disorders affecting the psychological life of the patients. This study describes how migraines can be overcome with or without medication. It also identifies the underlying causes of migraines, which are lack of emotional control and pain intensity, and explains how to deal with them. In this study, Compassion-Focused Therapy (CFT) was used: two essential aspects of compassion are the dimension of desire, which is the first aspect and focuses on the presence of pain and its causes; and healing is the second aspect which focuses on the willingness and action for advancing in the pursuit of reducing suffering.

\section{Introduction}

eadache is a prevalent complication (Uygunoglu \& Siva, 2016), and migraine is the most common type of headache (Woldeamanuel \& Cowan, 2016). Migraine headache is the third most common disease and the sixth most debilitating disease in the world

(Azimova, Skorobogatykh, Sergeev, \& Klimov, 2018). Migraine is a preliminary headache disorder causing more years of disability compared to other neurological complications (Azimva, Korobeynikova, Sergeev \& Naumova, 2013). The debilitating potential of migraine is associated with the frequency, severity, duration, and symptoms of the attacks (Gretchen \& Tietjen, 2017). Moreover, evidence shows that the prevalence of cardiovascular diseases, including hypertension, diabetes, and hyperlipidemia, is higher in migraine patients compared to the general public (Bigal \& Lipton, 2008).

From a clinical point of view, there are various migraine types, among which the two most important ones are migraine with an aura (classic migraine) and migraine without an aura (common migraine). The most common migraine type is the one without aura, which accounts for $80 \%$ of migraine patients (Rajabi \& Abbasi, 2015). In this type of migraine, the attacks are unilateral and characterized by pulsating episodes lasting 4 to 72 hours. This type of migraine is also accompanied by nausea, photophobia, and phonophobia (Rocket, Fernanda, Oliveira, Vanessa, \& Castro Merical, 2012). Migraine with aura consists of reversible episodes and neurological symptoms, and heredity plays a major role in this type of migraine (Pietrobon, 2005). Psychiatric disorders are highly comorbid in patients with migraines. While anxiety, depression, perfectionism, ambition, and extreme discipline in daily activities are among the characteristics of people with migraines (Oraky \& Tehrani, 2017).

On the other hand, pain is one of the most common symptoms forcing patients to seek help from healthcare centers. In addition to the problems and tensions caused by pain, it can affect various aspects of an individual's life due to its adverse effects on the patient, including treatment costs, the decline in job performance, and increased family problems (Shakeri, Shaeiri, \& Roshan, 2007). Research shows that pain can be divided into two categories based on its duration, i.e. acute pain (which is the result of a disease or injury and lasts for less than three months) and chronic pain (which lasts for more than three months). Those suffering from chronic pain will also encounter mental, biological, and social problems (Breivik, Collett, Ventafridda, Cohen, \& Gallacher, 2006).

One non-pharmaceutical strategy for coping with migraine is stress management (Ramadan \& Buchanan, 2006). The higher the patients' psychological flexibility and acceptance of this pain, the lower the level of disability they experience (McCracken \& Velleman, 2010). Goleman, Richard and Boyatzis (2014) believed that the individuals' ability to control emotions makes it easier for them to deal with life problems. Impaired emotional control methods can increase the likelihood of the devel- 
opment and continuation of psychological disorders. Besides, emotional control methods are the main source of understanding the emotional and behavioral dependencies of stresses and negative emotional events (Gross, 2002). Previous studies confirm the effectiveness of non-pharmaceutical and cognitive-behavioral approaches in treating headaches (Brown, Newman, Noad, \& Weatherby, 2012; Nicholson, Buse, Andrasik, \& Lipton, 2011). According to Neff and Germer's study (2013), there is a significant relationship between self-compassion and reduced anxiety, depression, perfectionism, neuroticism, preoccupations, and thought inhibitions. Moreover, self-compassion is related to proper self-regulation for dealing with stress.

Because of the high prevalence of migraines at all ages, the side effects and addictiveness of medications are essential for complete cure and the problem of not being used for all people. Non-pharmacological treatment is important for these patients. Therefore, searching for a trusted strategy with high effectiveness and negative consequences is needed, including compassion-focused therapy (Abdi Abdul, Parno Abdul, \& Azizi, 2014).

Compassion-Focused Therapy (CFT) was developed by Gilbert (2005). The basic definition of compassion, according to Gilbert, is "fundamental kindness accompanied by a deep awareness of the suffering of self and others along with desire and attempt for healing this suffering" (Neff \& Germer, 2013). According to this definition, two essential aspects of compassion are the dimension of desire, which is the first aspect and focuses on the presence of pain and its causes; and the healing, which focuses on the willingness and action for advancing in the pursuit of reducing suffering (Gilbert, 2013). There is a negative relationship between self-compassion and self-criticism, anxiety, and depression (Neff, 2003). Moreover, in another study, Breines et al. (2015) concluded that self-compassion could change negative beliefs. In CFT, unlike most treatments, people learn not to avoid or suppress their painful feelings, so they can, in the first place, recognize their experience and feel compassion for it (Irons \& Lad, 2017).

Emotional control involves methods used for reducing, increasing, or maintaining emotions (Gross, 2002). Jerman, Van der Linden, d'Acremont, and Zermatten, (2006) considered emotional control a natural component of humanity. Goleman et al. (2014) believed that people's ability to control their emotions could make it easier for them to deal with life problems. Gross and Thompson (2007) believed that people knowingly or unknowingly utilize various methods for emotion regulation, and some of these methods improve mental health.
For instance, distraction, repeating or writing the event, and boxing are some of the methods for emotional control (Cole, Dennis, Smith-Simon, \& Cohen, 2009). According to the mentioned discussions, the present study aimed to investigate the effectiveness of CFT for improving emotional control and reducing the severity of pain in patients with migraines.

\section{Methods}

The research method was quasi-experimental with a pre-test, post-test design and a control group. The statistical population included all patients with neurological migraines referred to Isfahan Al-Zahra Hospital, Isfahan City, Iran, from May 5 to July 6, 2019. In this research, a total of 30 patients were selected as a sample according to a convenience sampling method and were divided into two experimental and control groups $(n=15$ per group) through random assignment. Therefore, the sample size is 30 people. To confirm the diagnosis, all the participants were evaluated using the Migraine Disability Assessment (MIDAS) questionnaire to verify their migraines. Therefore, the physicians' diagnosis and obtaining a score from the MIDAS questionnaire were the criteria for enrolling them. The experimental group received eight 90-min sessions of CFT, and both groups took the post-test after finishing the training sessions. Table 1 presents a summary of sessions. Therefore, the criterion for leaving the experimental group was set based on the absence in more than two treatment sessions. The data analysis involved descriptive and inferential statistics, including mean, standard deviation, Multivariate Analysis of Covariance (MANCOVA), and Analysis of Covariance (ANCOVA). Also, to observe the ethical considerations before the meetings and taking the pretest, written consent was obtained from the samples. At the end of the treatment sessions, it was decided to hold 4 sessions for the control group, and a summary of this treatment be taught to them. The code of ethics of this research is IR.PNU.REC.1398.030.

\section{Research instruments}

\section{Emotional Control Questionnaire (ECQ)}

Roger and Nesshoever (1987) developed the initial construct for the Emotional Control Questionnaire (ECQ), and Roger and Najarian (1989) amended the questionnaire. The amended version was the one used in the current study. The ECQ has four subscales and 56 items. The subscales include emotional inhibition, aggression control, rehearsal (or rumination), and benign control. Rafiee Niya, Rasoulzadeh Tabatabaei, and 
Table 1. Compassion-Focused Therapy (CFT) protocol

\begin{tabular}{|c|c|c|c|c|}
\hline Session & Objectives & Content & Homework & Expected Behavior \\
\hline First & $\begin{array}{l}\text { Getting familiar } \\
\text { with the general } \\
\text { principles of the } \\
\text { treatment method }\end{array}$ & $\begin{array}{l}\text { Establishing initial relations, grouping the partici- } \\
\text { pants, reviewing the structure of the sessions, under- } \\
\text { standing the basic principles of compassion-focused } \\
\text { therapy, evaluating the extent of neurological mi- } \\
\text { graine and the self-compassion of the participants, } \\
\text { describing and explaining migraine and factors relat- } \\
\text { ed to its symptoms, conceptualizing self-compassion } \\
\text { training }\end{array}$ & $\begin{array}{l}\text { Recording the instanc- } \\
\text { es of migraine due to } \\
\text { lack of self-compassion } \\
\text { and compassion to- } \\
\text { wards others in ev- } \\
\text { eryday behavior and } \\
\text { behaving towards self } \\
\text { and others }\end{array}$ & $\begin{array}{l}\text { Identifying and com- } \\
\text { plete understanding } \\
\text { of migraine and the } \\
\text { effects of compas- } \\
\text { sion on migraine }\end{array}$ \\
\hline Second & $\begin{array}{l}\text { Understanding the } \\
\text { components of } \\
\text { self-compassion }\end{array}$ & $\begin{array}{l}\text { Identifying and introducing the components of com- } \\
\text { passion, evaluating each component of compassion } \\
\text { in the participants and identifying its characteristics; } \\
\text { understanding the characteristics of compassionate } \\
\text { people, and evaluating the self-compassion of the } \\
\text { participants }\end{array}$ & $\begin{array}{l}\text { Recording the compo- } \\
\text { nents of self-compas- } \\
\text { sion or compassion } \\
\text { towards others in ev- } \\
\text { eryday events and be- } \\
\text { haviors }\end{array}$ & $\begin{array}{l}\text { Identifying and un- } \\
\text { derstanding the } \\
\text { components of self- } \\
\text { compassion }\end{array}$ \\
\hline
\end{tabular}

Reviewing the previous session's homework, promoting the sense of warmth and kindness towards self, promoting and understanding the fact that others Teaching and pro- promoting and understanding the fact that others moting self-com- sense of shared human characteristics versus selfpassion among the destructive feelings and embarrassment), teaching participants self-sympathy, shaping and establishing more diverse feelings relative to the issues of the individuals to increase self-care and paying attention to one's health

Reviewing the previous session's homework; encouraging participants to promote self-knowledge Self-knowledge and evaluate their personalities in terms of self-comand identifying the factors of selfcriticism passion or lack thereof and utilizing compassionate exercises (the value of self-compassion, sympathy, and empathy towards self and others); accepting mistakes and forgiving self for accelerating change

Reviewing the previous session's homework, introducing and implementing compassionate mind Correcting and ex- training (forgiveness, acceptance without judgment, panding self-com- patience training), teaching the acceptance of issues; passion accepting changes, and tolerating difficult situations considering the variable nature of life and its difficult situations

Reviewing the previous session's homework, a practical exercise of creating compassionate images, Teaching the styles teaching the styles and methods of expressing com-

Sixth and methods of passion (verbal compassion, practical compassion, expressing com- temporary compassion, and continuous compaspassion sion), utilizing these methods in everyday life for family members and friends, teaching the promotion of valuable and transcendental feelings
Recording the roots or Identifying and uncomponents of self- derstanding the compassion in a more components of detailed manner in self-compassion in everyday events and a more profound behaviors manner

Recording daily mistakes (related to compassion or migraine) and identifying their Promoting self-compassion

causes

Recording the instances of forgiveness and acceptance without judgment in daily challenges and utilizing the Improving and expanding self-compassion three-chair method

Using compassion in A feeling of self-valeveryday activities ue, self-respect, and respect for others
Reviewing the previous session's homework, teachTechniques for ex- ing how to write compassionate letters to self and

Seventh pressing compassion

others, teaching how to record and take daily notes of real-life situations based on compassion and the individual's behavior in that situation

Teaching and exercising the skills; reviewing and applying the skills taught in previous sessions to help

Eighth Evaluation and application participants adopt various methods to their living conditions; and finally, summarizing and providing strategies for maintaining and utilizing compassion in everyday life
Writing a compassion- Improving self-comate letter for self and passion and selfothers value

Reviewing previous homework and recording the instances of self-compassion in daily challenges
Promoting and developing self-compassion and compassion for others 
Azadfallah (2005) reported the reliability of this scale using the internal consistency method and calculating the Cronbach $\alpha$ coefficients for the entire scale and the abovementioned subscales as $0.68,0.70,0.76,0.77$, and 0.58 , respectively. The answers for each item include the options of "true" or "false", where "true" is scored 1 and "false" is scored 0. However, items 24, 25, 26, 28, 29, $30,36,37,40,42,45,47,17,18,19,21,23,2,5,7,9,10$, $11,12,49,51,52,53,55$, and 56 are scored in reverse, where "true" is scored 0 and "false" is scored 1 .

Questionnaire of von Korff for Grading The Severity of Chronic Pain

This scale was developed by von Korff et al. in 1992 for measuring the severity of chronic pain. The average pain severity during the last four weeks is measured by an 11-point scale from 0 (no pain) to 10 (worst possible pain). This scale is often used in studies related to pain. A host of evidence supports its validity for measuring the severity of pain in all pain complications and all populations (Jensen \& Karoly, 2000). In this questionnaire, three components are evaluated, i.e. severity or intensity of pain, the duration of pain, and the extent of the disability caused by the pain. In a study by Smith and Schwartz (1997) on this scale using 400 patients suffering from pain, the internal reliability of the scale was found 0.91 , and the validity of all the questions more than 0.75 .
The Migraine Disability Assessment (MIDAS) Questionnaire

This questionnaire was developed by Stewart et al. (2000). This questionnaire calculates the number of missed days or the number of days with limited activities due to headaches during the last three months. The total score for the questionnaire is obtained by adding up the scores for individual questions, and respondents are categorized into four groups based on their final score. The first group with a score of 0 to 5 is in the group with "little or no disability", and this group does not need a particular treatment intervention. The second group with a score of 6 to 10 is considered a group with "mild disability", requiring mild treatment. The third group with a score of 11 to 20 is considered a group with "moderate disability", and the fourth group with a score higher than 21 is considered a group with "severe disability", both of which require immediate treatment. The validity of this questionnaire is 0.77 , while its reliability is 0.83 .

\section{Results}

In the current study, the descriptive data for the participants, including gender, average age, and educational level, were evaluated, while at the inferential level, the collected data were analyzed using the Analysis of Vari-

Table 2. Descriptive findings of emotional control and the severity of pain in the experimental and control groups

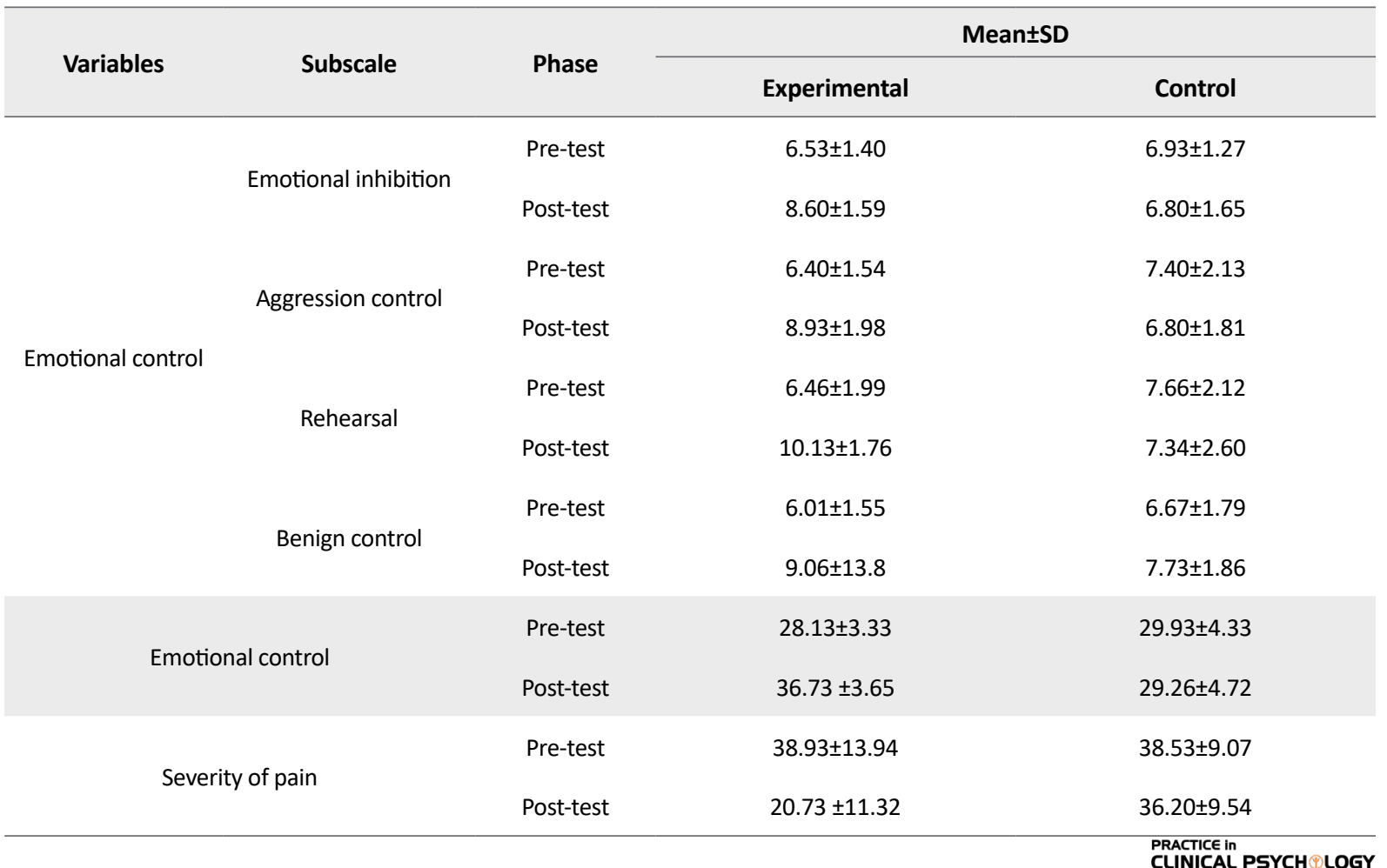


Table 3. Wilks's Lambda test to evaluate the difference between the means of the emotional control group and the severity of pain

\begin{tabular}{cccccr}
\hline Source & Value & df1 & df2 & F & P \\
\hline Wilks's Lambda test & 0.20 & 2 & 25 & 47.96 & 0.01 \\
\hline & & & & PLANICAL PSYCH L LOGY
\end{tabular}

ance (ANOVA). According to the descriptive statistics, $80 \%$ of the participants were female. The average age of the participants was 34.43 years, with a standard deviation of 11.07 years. Moreover, $23.3 \%$ of the participants had a secondary school degree, $30 \%$ had a high school diploma, and $46.7 \%$ had a bachelor's degree.

In the next analysis, the effectiveness of CFT was evaluated for emotional control and severity of pain. Before performing the one-way Analysis of Covariance (ANCOVA), it is necessary to satisfy the assumption of this analysis. At first, the first condition, i.e. the discreteness of the variables, was evaluated. Then, the second condition was assessed using the Shapiro-Wilk test to confirm the normalcy of the data. Afterward, using the non-significance results of Levene's test, the homoscedasticity condition was satisfied. Finally, the lack of significant difference between the study measures in terms of regression slopes was confirmed as the fourth assumption of the analysis of covariance.

According to Table 2, the average pre-test score of pain severity for the experimental group was 38.93 , while its average post-test score was 20.73. Moreover, the average pre-test and post-test scores for pain severity for the control group were 38.53 and 36.20 , respectively. Besides, the average pre-test score of emotional control for the experimental group was 28.13, while the average post-test score was 36.73 . However, the average pre-test and post-test scores of emotional control for the control group were 29.93 and 29.26 , respectively.
Based on the value of $0.20, \mathrm{~F}=47.96$, and the significance level of $\mathrm{P}<0.01$, the average scores of the experimental and control groups are different at least for one of the measures of emotional control and pain severity after eliminating the effects of the covariate variable (Table 3 ). To test the main hypothesis positing the effectiveness of CFT on emotional control and pain severity of migraine patients, Analysis of Covariance (MANCOVA) was used.

According to the F statistic values for the group source (significant at the level of $\mathrm{P}<0.01$ ), CFT training affected emotional control and pain severity by improving emotional control and mitigating pain severity. Based on the $\eta^{2}$ coefficient, $75 \%$ of the variance in emotional control and $39 \%$ of the variance in pain severity are affected by the independent variable, i.e. CFT, proving the main hypothesis of the study (Table 4).

\section{Discussion}

The present study aimed to investigate the effectiveness of CFT for improving emotional control and reducing the severity of pain in patients with migraines. The results obtained from the current study indicate that CFT sessions significantly influenced improving emotional control and reducing pain severity of migraine patients. The finding of this study is consistent with findings of Goleman et al. (2014), Neff and Germer (2013), Rajabi and Abbasi (2015), Gilbert (2009), and Breines et al. (2015), which all show the effectiveness of CFT for improving emotional control. It should be noted that people

Table 4. Results of analysis of covariance for the impact of compassion-focused therapy on emotional control and the severity of pain

\begin{tabular}{|c|c|c|c|c|c|c|c|}
\hline Source & SS & df & MS & $\mathbf{F}$ & $\mathbf{P}$ & Partial $\eta^{2}$ & Power \\
\hline Emotional control & 308.76 & 1 & 308.76 & 43.52 & 0.01 & 0.62 & 1.00 \\
\hline Group & 578.26 & 1 & 578.26 & 81.51 & 0.01 & 0.75 & 1.00 \\
\hline Error & 184.45 & 26 & 7.09 & & & & \\
\hline Severity of pain & 435.43 & 1 & 435.43 & 4.31 & 0.04 & 0.14 & 0.52 \\
\hline Group & 17.37 .52 & 1 & 17.37 .52 & 17.21 & 0.01 & 0.39 & 0.97 \\
\hline Error & 2624.93 & 26 & 100.95 & & & & \\
\hline
\end{tabular}


with the ability to control emotions are more capable of identifying their emotions, understanding the implied concepts of these emotions, and expressing their emotional states to others in a more effective way (Goleman et al., 2014). Moreover, CFT increases wellbeing, which helps individuals gain a feeling of care and appropriate relation, thereby resulting in a relaxed emotional state (Neff, Kirkpatrick, \& Rude, 2007). In other words, selfcompassion, which has recently been proposed as an alternative for self-value in the healthy attitude and relation to self, plays a useful role in controlling emotions and the attitudes of the individuals towards life problems and life events. The compassion-based attitude helps individuals feel a connection and relation between themselves and others, overcoming isolation and rejection through this emotion. The soothing (healing) system acts as a natural regulator, reducing the perceptions of threats and dangers in the individual (Neff \& McGehee, 2010). Accordingly, CFT stimulates the soothing system to reduce the individual's perceptions of danger and threats and instead increases caring, empathy, and compassionate behaviors with self and others (Gilbert, 2009).

Moreover, the individual's control over expressing positive emotions, having a sense of emotional balance, and possessing characteristics such as optimism, sense of value and meaning, self-acceptance, and accepting others (which are all confirmed by CFT) can be effective factors for improving the emotional control of patients. Besides, based on the emotion regulation style approach, CFT can act as a positive emotion regulation style, reducing the negative emotions of the individual and replacing them with positive emotions. Therefore, it seems that the depression of the individual can be mitigated through this emotional self-regulation (Diedrich, Grant, Hofmann, Hiller, \& Berking, 2014).

Concerning the effectiveness of CFT on reducing pain severity, the results indicate that mindfulness, as a component of CFT, is compatible with the inherent nature of human beings. So, it can affect individuals' emotional system, namely, their thoughts, physical senses, raw emotions, and impulses of action. However, it can change the way they look at life, and increase their relationships with themselves, others, and the world through a compassionate and realistic acceptance (Williams \& Penman, 2012). CFT can help people suffering from chronic headaches to regulate their emotions based on the relationship between pain and feeling to prevent bias in processing information, leading to negative emotions. In turn, they will be able to adapt to their disease more efficiently. Furthermore, the individuals' capacity for selfregulating their emotions can be the source of their cru- cial difference in tolerating pain and suffering, through which individuals manage to separate the experience of pain from emotional pain reactions.

Moreover, Wicksell, Melin, Lekander, and Olsson (2009) showed that accepting pain is a stronger predictor for distress and disability compared to several other methods of coping with pain. Besides, Aldrich, Eccleston and Crombez (2000) believed that one of the similarities of individuals suffering from chronic pain involves numerous failed experiences for controlling their pain. Therefore, based on the literature, this idea might be useful that accepting pain instead of trying to control it can be accompanied by a higher level of adaptability. The current study exclusively evaluated migraine patients. Therefore, caution must be exercised when generalizing the results of other similar diseases. Moreover, the patients filled out the questionnaires twice, i.e. once in the pre-test and once in the post-test. Therefore, it is likely that factors such as the pre-test effect, fatigue, repetition, and reduced motivation may have affected their answers. It is recommended that physicians encourage patients to use psychological treatments while prescribing medications for such patients. Moreover, it is recommended that CFT training classes be organized for patients suffering from migraines.

\section{Conclusions}

The results of the current study show that CFT reduces migraine pain and improves emotional control. It can be said that CFT is, directly and indirectly, useful for relieving pain, and utilizing this therapy as the main course of treatment or a supplementary therapeutic method can help improve migraine in these patients.

\section{Ethical Considerations}

\section{Compliance with ethical guidelines}

This research was approved by Payame Noor University, Tehran (Code: IR.PNU.REC.1398.030). To observe the ethical considerations before the meetings and taking the pretest, written consent was obtained from the samples.

\section{Funding}

This research did not receive any grant from funding agencies in the public, commercial, or non-profit sectors.

\section{Authors' contributions}

All authors equally contributed to preparing this article. 


\section{Conflict of interest}

The authors declared no conflict of interest.

\section{References}

Azimova, J., Skorobogatykh, K., Sergeev, A., \& Klimov, E. A. (2018). Migraine and depression: A comparative assessment of the efficacy and safety of antidepressants in patients with migraine. Journal of Neurology \& Stroke, 8(4), 208-12. https:/ / www.researchgate.net/profile/Eugene-Klimov/publication/326583129

Aldrich, S., Eccleston, C., \& Crombez, G. (2000). Worrying about chronic pain: Vigilance to threat and misdirected problem solving. Behaviour Research and Therapy, 38(5), 457-70. [DOI:10.1016/ S0005-7967(99)00062-5]

Azimva J. E., Korobeynikova N. S., Sergeev A., \& Naumova, E. (2013). Effects of MTHFR gene polymorphism on the clinical and electrophysiological characteristics of migraine. BMC Neurology, 13(1), 103. [DOI:10.1186/1471-2377-13-103] [PMID] [PMCID]

Abdi Abdul, S., Parno Abdul, H., \& Azizi, M. (2014). [The effect of eight weeks of high-intensity aerobic exercise on migraine headache indices (Persain)]. Quarterly of the Horizon of Medical Sciences (HMS), 20(3), 133-8. https://www.sid.ir/fa/journal/ViewPaper.aspx?id=237115

Bigal, M. E., \& Lipton, R. B. (2008). The prognosis of migraine. Current Opinion in Neurology, 21(3), 301-8. [DOI:10.1097/ WCO.0b013e328300c6f5] [PMID]

Breines, J. G., McInnis, C. M., Kuras, Y. I., Thoma, M. V., Gianferante, D., \& Hanlin, L., et al. (2015). Self-compassionate young adults show lower salivary alpha-amylase responses to repeated psychosocial stress. Self and Identity, 14(4), 390-402. [DOI:10.1080 /15298868.2015.1005659] [PMID] [PMCID]

Breivik, H., Collett, B., Ventafridda, V., Cohen, R., \& Gallacher. D. (2006). Survey of chronic pain in Europe: Prevalence, impact on daily life, and treatment. European Journal of Pain, 10(4), 287-333. [DOI:10.1016/j.ejpain.2005.06.009] [PMID]

Brown, H., Newman, C., Noad, R., \& Weatherby, S. (2012). Behavioural management of migraine. Annual Indian Academic Neurology, 15(Suppl 1), 78-82. [DOI:10.4103/0972-2327.100018] [PMID] [PMCID]

Cole, P. M., Dennis, T. A., Smith-Simon, K. E., \& Cohen, L. H. (2009). Preschoolers' emotion regulation strategy understanding: Relations with emotion socialization and child self-regulation. Social Development, 18(2), 324-52. [DOI:10.1111/j.14679507.2008.00503.x

Diedrich, A., Grant, M., Hofmann, S. J., Hiller, W., \& Berking, B. (2014). Selfcompassion as an emotion regulation strategy in major depressive disorder. Behavior Research and Therapy, 58, 43-51. [DOI:10.1016/j.brat.2014.05.006] [PMID]

Irons, C., \& Lad, S. (2017). Using compassion focused therapy to Work with shame and self-criticism in complex trauma. Australian Clinical Psychologist, 3(1), 47-54. https://acp.scholasticahq. com/article/1743-
Gilbert, P. (2005). Compassion conceptualization, research and use in psychotherapy. New York: Routledge Publication. [DOI:10.4324/9780203003459]

Gilbert, P. (2009). An introduction to compassion focused therapy. Advances in- Psychiatric Treatment, 15(3), 199-208. [DOI:10.1192/apt.bp.107.005264]

Gilbert, P. (2013). Mindful compassion-how the science of compassion ca help you understand your emotions, live in the present, and connect deeply with others. London: Constable \& Robinson https:/ / books.google.com/books?id=3XJzngEACAAJ\&dq=

Goleman, D., Richard, E., Boyatzis, A.M. (2014). Primal leadership: learning to lead with emotional intelligence. Boston: Harvard Business School Press.

Gretchen, E., \& Tietjen, M. D. (2017). Risk factors and prognosis of chronic migraine [MD. dissertation]. Toledo: University of Toledo. http://www.upandrunningnetworks.com/files/ C158_2.pdf

Gross, J. J. (2014). Emotion regulation: Conceptual and empirical foundations. In J. J. Gross (Ed.), Handbook of Emotion Regulation (p. 3-20). New York City: The Guilford Press. https:// psycnet.apa.org/record/2013-44085-001

Gross, J. J. (2002). Emotion regulation: Affective, cognitive and social consequences. Psychophysiology, 39(3), 191-281. [DOI:10.1017/S0048577201393198] [PMID]

Gross, J. J., \& Thompson, R. A. (2007). Emotion Regulation: Conceptual Foundations. In J. J. Gross (Ed.), Handbook of emotion regulation (p. 3-24). New York: The Guilford Press. https:// psycnet.apa.org/record/2007-01392-001

Jermann, F., Van der Linden, M., d'Acremont, M., \& Zermatten, A. (2006). Cognitive Emotion Regulation Questionnaire (CERQ). European Journal of Psychological Assessment, 22(2), 126-31. [DOI:10.1027/1015-5759.22.2.126]

Jensen, M., \& Karoly, P. (2000). Self-report scales and procedures for assessing pain in adults. In: Turk DC, Melzack R, (Eds). Handbook ofpain assessment. New York: Guilford. https:/ / scirp. org $/$ reference $/$ referencespapers.aspx?referenceid $=1966917$

Azimova, J., Skorobogatykh, K., Sergeev, A., \& Klimov, E. A (2018). Migraine and depression: a comparative assessment of the efficacy and safety of antidepressants in patients with migraine. Journal of Neurology \& Stroke, 8(4), 208-12. https:// www.researchgate.net/profile/Eugene-Klimov/publication/326583129

McCracken, L. M., \& Velleman, S. C. (2010). Psychological flexibility in adults with chronic pain: A study of acceptance, mindfulness, and values-based action in primary care. Pain, 148(1), 141-7. [DOI:10.1016/j.pain.2009.10.034] [PMID]

Neff, K. D., \& McGehee, P. (2010). Self-compassion and psychological resilience among adolescents and young adults. Self and Identity, 9(3), 225-40. [DOI:10.1080/15298860902979307]

Neff, K. (2003). Self-compassion: An alternative conceptualization of a healthy attitude toward oneself. Self and Identity, 2(2), 85-101. [DOI:10.1080/15298860309032]

Neff, K. D. (2003). The development and validation of a scale to measure self-compassion. Self and Identity, 2(3), 223-50. [DOI:10.1080/15298860309027] 
Neff, K. D., \& Germer, C. K. (2013). A pilot study and randomized controlled trial of the mindful self-compassion program. Journal of Clinical Psychology, 69(1), 28-44. [DOI:10.1002/ jclp.21923] [PMID]

Neff, K. D., Kirkpatrick, K. L., \& Rude, S. S. (2007). Self-compassion and adaptive psychological functioning. Journal of Research in Personality, 41(1), 139-54. [DOI:10.1016/j. jrp.2006.03.004]

Nicholson, R. A., Buse, D. C., Andrasik, F., \& Lipton, R. B. (2011). Nonpharmacologic treatments for migraine and tension-type headache: How to choose and when to use. Current Treatment Options in Neurology, 13(1), 28-40. [DOI:10.1007/s11940-0100102-9] [PMID]

Oraki, M., \& Tehrani, N. V. (2017). [The Comparision of effectiveness of biofeedback and Neuro biofeedback training on reduction of headache migraine (Persian)]. Neuropsychology, 2(7), 107-18. http://clpsy.journals.pnu.ac.ir/m/article_3796_ 3cc7e581302c4349d8b176a09ec660dc.pdf

Pietrobon, D. (2005). Migraine: New molecular mechanisms. The Neuroscientist, 11(4), 373-86. [DOI:10.1177/1073858405275554] [PMID]

Rafiee Niya, P., Rasoulzadeh Tabatabaei, K., \& Azadfallah, P. (2006). [Relation between the styles of_emotional expression and General Health in the collegians (Persian)]. Journal of Phychology, 10(1), 84-105.

Rajabi, S., \& Abbasi, Z. (2015). [The epidemiology of migraine headaches and the efficacy of Fordyce's happiness training on reducing symptoms of migraine and enhancing happiness (Persian)]. Contemporary Psychology, Biannual Journal of the Iranian Psychological Association, 9(2), 89-100. http://bjcp. ir/browse.php?a_id=613\&sid=1\&slc_lang=en

Ramadan, N. M., \& Buchanan, T. M. (2006). New and future migraine therapy. Pharmacology \& Therapeutics, 112(1), 199-212. [DOI:10.1016/j.pharmthera.2005.04.010] [PMID]

Rocket, T., Fernanda, C., Oliveira, E., Vanessa, R., \& Castro Merical, L. (2012). Nutrition. Reviews, 70, 337-56. [DOI:10.1111/ j.1753-4887.2012.00468.x] [PMID]

Roger, D., Najarian, B. (1989). The construction and validation of a new scale for measuring emotion control. Personality and Individual Differences, 10(8), 845-53. [DOI:10.1016/01918869(89)90020-2]

Roger, D., \& Nesshoever, W. (1987). The construction and preliminary validation of a scale for measuring emotional control. Personality and Individual Differences, 8(4), 527-34. https://www.sciencedirect.com/science/article/abs/ pii/0191886987902157

Sajadi-Nejad, M. S., Mohammadi, N., \& Ashjazadeh, N. (2009). [Effect of cognitive-behavioral group therapy on perception of stressors in recurrent headache patients (Persian)]. Journal of Shahrekord University of Medical Sciences, 11(2), 8-15. http:/ / eprints.skums.ac.ir/5757/

Shakeri, R., Shaeiri, M. R., \& Roshan, R. (2007). [The effect of biofeedback training on experimental pain according to perfectionism (Persian)]. Journal of Bulletin of Environment, Pharmacology and Life Sciences, 11(1), 43-59.

Smith, P. B., \& Schwartz, S. H. (1997). Values. In: J. W., Berry, M H., Segall \& C. Kagiticibasi, (Eds.). Hand book of cross-cultural psychology (Vol 3, pp 77-118). Boston: Allyn \& Bacon.
Stewart, W. F., Lipton, R. B., Kolodner, K. B., Sawyer, J., Lee, C. \& Liberman, J. N. (2000). Validity of the Migraine Disability Assessment (MIDAS) score in comparison to a diary-based measure in a population sample of migraine sufferers. Pain, 88(1), 41-52. https://www.sciencedirect.com/science/article/abs/pii/S0304395900003055

Uygunoglu, U., \& Siva, A. (2016). Epidemiology of Headache. In Pharmacological Management of Headaches (pp. 7-18): Springer. [DOI:10.1007/978-3-319-19911-5_2]

Wicksell, R. K., Melin, L., Lekander, M., \& Olsson, G. L. (2009). Evaluating the effectiveness of exposure and acceptance strategies to improve functioning and quality of life in longstanding pediatric pain-a randomized controlled trial. Pain, 141(3), 248-57.[DOI:10.1016/j.pain.2008.11.006] [PMID]

Williams, M., \& Penman, D. (2011). Mindfulness: A practical guide to finding peace in a frantic world. UK: Hachette. https:/ / books. google.com/books?id=

Woldeamanuel, Y., \& Cowan, R. (2016). Worldwide migraine epidemiology: Systematic review and meta-analysis of 302 community-based studies involving 6,216,995 participants (P6. 100). Neurology, 86(16 Supplement), 6. [DOI:10.1016/j. aogh.2016.04.530] 
This Page Intentionally Left Blank 